\title{
プロセス制御系への多変数モデル規範形 適応手法の一応用
}

\author{
小西克 信*.大塚 浩 明*.芳 村敏 夫*・石原弘一** \\ An Application of Multivariable Model Reference Adaptive Techniques \\ to a Process Control System
}

\author{
Katsunobu Konishi*, Hiroaki OtsukA*, Toshio Yoshimura* \\ and Hirokazu IsHiHARA**
}

This paper presents an application of the multivariable model reference adaptive control (MRAC) approach to a three-input three-output process control system. Since this system has small leading coefficients, the control inputs vibrate violently when the basic MRAC scheme is applied. In order to reduce the input vibrations, the basic MRAC scheme is modified so that the transfer function matrix between the control inputs and the system disturbances in the closed loop includes some adjustable parameters, and two methods to determine these parameters are proposed. Experimental results show that good performance in the input smoothing are obtained by the proposed MRAC scheme without degrading the tracking ability to the model reference output sequences.

Key Words: process control, multivariable discrete system, adaptive control, input smoothing

\section{1. 緒言}

モデル規範形適応制御（MRAC）に関してはてれま でに数多くの研究が行われ ${ }^{1), 2)}$, 安定解析や同定法な どの基礎理論が確立されるとともに，種々の分野への 応用 ${ }^{3)}$ を通じてその有用性が認識されてきている。し

†第 29 回自動制御連合講演会で発表（昭 $61 \cdot 11$ )

* 德島大学工学部 徳島市南常三島町 2-1

** 高松工業高等専門学校 高松市勅使町 355

* Faculty of Engineering, The University of Tokushima, Tokushima

** Takamatsu National College of Technology, Takamatsu

(Received December 1, 1986)

(Revised March.31, 1987)
かしながら，とれらの研究の大部分はプラント出力の 規範モデル出力への追従のみを論じたものであり，入 力の挙動に関してはそれが有界であるとと以外にはほ とんど考慮されなかった，そこで著者らは，1 入力・ 1 出力の簡単な圧力制御系での実験を通して入力の平 滑化という視点が必要であることを述べ，平滑化に関 する基本的なアルゴリズムを提案した ${ }^{4)}$,5). 本論文は, このアルゴリズムを一般化し, 3 入力・ 3 出力のプロ セス制御系へ応用した結果を述べたものである.

よく知られているように, MRAC では入力を計算 する際, 入力の係数行列での除算を必要とする. した がって，係数行列の高周波ゲインが小さい場合には， 系に作用する微小な外乱が増幅されて重曽し，乙れが 入力の不必要な振動を引き起こす．乙の振動を除去す るために，ここでは制御器の構造の中に可調節パラメ 一夕を導入し, 閉ループ系における外乱から入力まで の伝達関数の高周波ゲインを下げるとととした.すな わち, MRAC では伝達関数行列を $\alpha^{-1} B$ とするとき, むだ時間 $d$ を処理するために $P^{\circ}\left(z^{-1}\right)=\alpha\left(z^{-1}\right) R^{\circ}\left(z^{-1}\right)$ $+z^{-d} S^{\circ}\left(z^{-1}\right)$ の形の恒等式が使われるが6)，乙れを $F\left(z^{-1}\right) P\left(z^{-1}\right)=\alpha\left(z^{-1}\right) Q_{r}\left(z^{-1}\right) R\left(z^{-1}\right)+z^{-d} Q_{s}\left(z^{-1}\right) S\left(z^{-1}\right)$ と分割し, $F\left(z^{-1}\right), P\left(z^{-1}\right), Q_{r}\left(z^{-1}\right), Q_{s}\left(z^{-1}\right)$ の要素 多項式の係数を調節するあのである. 入力の平滑化は 追従誤差を増大させるため，調節の方法はそれぞれの 系によって異なるであろうが，圧力・水位・流量を制 御量とする 3 入出力系での実験を通じて有効と思われ たふたつの調節法を述べた。 また，実験の場合とは特 性の異なる系への適用例として，むだ時間が 2 [step] の 3 次のスカラー系に対するディジタルシミュレーシ ョンの結果を示し, 本手法の妥当性を検討した. 


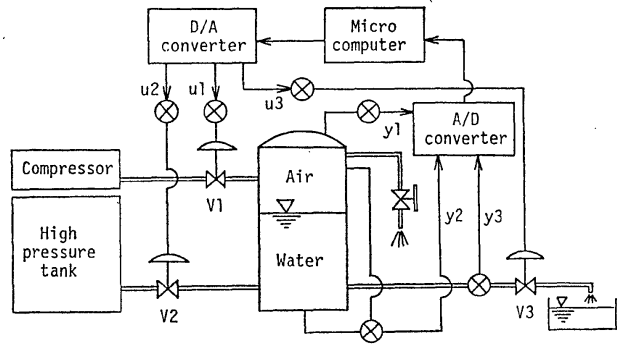

Fig. 1 Shematic diagram of the control system

\section{2. 制御対象のモデリング}

\section{1 制御対象の概要}

制御対象の概要を Fig. 1 亿示す. ここで, 制御量 はタンク内の空気圧, 水位およびタンクからの流出水 量であり, それぞれ圧力計, 差圧計および電磁流量計 で測定されて電圧 $y_{1}, y_{2}, y_{3}$ 亿変換される. 操作量 は，制御弁 $v_{1} ， v_{2} ， v_{3}$ の開度であり，マイコンから の指令電圧 $u_{1}, u_{2}, u_{3}$ によって調節される. これら の制御弁は非線形性を有し， $u_{1}$ と $y_{1}$ の間の定常入出 力特性扔よび $v_{2}, v_{3}$ の流量特性は Fig. 2 および Fig. 3 のようになっている. な扔，タンクの断面積 は $0.58 \mathrm{~m}^{2}$, 水位之 $y_{2}$ の関係は $1 \mathrm{~mm}$ あたり 0.0131 $\mathrm{V}$ の比例関係である。また，マイコンインタフェイ スとしての A/D，D/A 変換器の精度は 12 bit（0〜10 V) である.

$u_{1} \rightarrow y_{1}$ と $u_{3} \rightarrow y_{3}$ のそれぞれのステップ応答波形は, むだ時間を有する1次遅れ波形で近似できる. したが って, Fig. 1から明らかな変数間の相互作用を考慮す れば，平衡点まわりでの入出力関係はつぎのようにな る.

$$
\left(1+T_{1} \frac{d}{d t}\right) \tilde{y}_{1}(t)=K_{11} \tilde{u}_{1}\left(t-L_{1}\right)+K_{12} \frac{d \tilde{y}_{2}}{d t}
$$

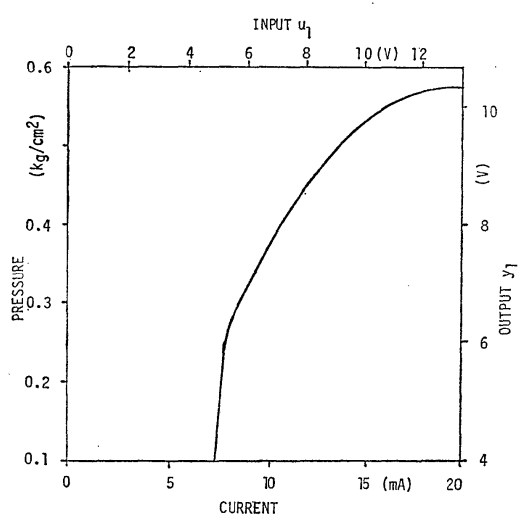

Fig. 2 Input-output relation of the pressure control loop at steady state

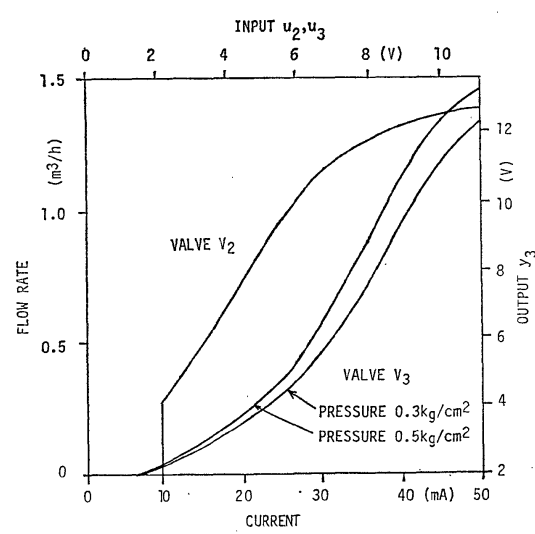

Fig. 3 Characteristics of the control valves $V_{2}$ and $V_{3}$

$$
\begin{aligned}
& \frac{d \tilde{y}_{2}(t)}{d t}=K_{21} \tilde{u}_{2}\left(t-L_{2}\right)-K_{22} \tilde{y}_{1}(t)-K_{23} \tilde{y}_{3}(t) \\
& \left(1+T_{3} \frac{d}{d t}\right) \tilde{y}_{3}(t)=K_{31} \tilde{u}_{3}\left(t-L_{3}\right)+K_{32} \tilde{y}_{1}(t)
\end{aligned}
$$

ここで， $\tilde{y}_{1}$ は $y_{1}$ の平衡值からの偏差であり, $\tilde{y}_{2}, \tilde{y}_{3}$, 颉などについてあ同様である. 各係数の值は, 平衡值 を $y_{1}=7.5, y_{2}=8, y_{3}=8.5$ としてステップ応答波形 および Fig. 2, Fig. 3 の定常特性から計算すると, $T_{1} \fallingdotseq 150[\mathrm{~s}], T_{3}=3.5[\mathrm{~s}], L_{1} \fallingdotseq L_{2} \fallingdotseq L_{3} \fallingdotseq 1[\mathrm{~s}], K_{11} \fallingdotseq$ $0.9, \quad K_{12} \fallingdotseq 4 T_{1}[\mathrm{~s}], \quad K_{21} \fallingdotseq 0.001\left[\mathrm{~s}^{-1}\right], \quad K_{22} \fallingdotseq 0\left[\mathrm{~s}^{-1}\right]$, $K_{23} \fallingdotseq 0.0006\left[\mathrm{~s}^{-1}\right], K_{31} \fallingdotseq 2, K_{32} \fallingdotseq 0.5$ の程度である.

\section{2 線形離散時間モデル}

(1)〜（3)式に対応する厳密な離散時間モデルは, $\left[\tilde{y}_{1}, \tilde{y}_{2}, \tilde{y}_{3}\right]^{\mathrm{T}}$ を状態変数, $\left[\tilde{u}_{1}, \tilde{u}_{2}, \tilde{u}_{3}\right]^{\mathrm{T}}$ を入力変数之 する状態変数表示によって容易に得られるが7)，之れ は $3 \times 3$ の係数行列を 3 個含むため, 合計 27 個のパラ メータを含むモデルとなる．しかしながら，27 個の パラメータというのは (1)〜 (3) 式に含まれる $T$, $L, K$ 合計 12 個に比べてあ過剩之考えられるから， ここでは変数間の相互作用およびむだ時間 $L_{1} \sim L_{3}$ を 考慮しうる最屯簡単なモデルとして，

$$
\begin{gathered}
{\left[\begin{array}{ccc}
1+a_{11} z^{-1} & 0 & 0 \\
0 & 1+a_{21} z^{-1} & 0 \\
0 & 0 & 1+a_{31} z^{-1}
\end{array}\right]\left[\begin{array}{l}
y_{1}(t+1) \\
y_{2}(t+1) \\
y_{3}(t+1)
\end{array}\right]} \\
=\left[\begin{array}{ccc}
b_{110}+b_{111} z^{-1} & b_{120} & b_{130} \\
0 & b_{220}+b_{221} z^{-1} & b_{230} \\
0 & 0 & b_{330}+b_{331} z^{-1}
\end{array}\right] \\
\quad \times\left[\begin{array}{l}
u_{1}(t) \\
u_{2}(t) \\
u_{3}(t)
\end{array}\right]+\left[\begin{array}{l}
c_{1} \\
c_{2} \\
c_{3}
\end{array}\right]+\left[\begin{array}{c}
\varepsilon_{1}(t+1) \\
\varepsilon_{2}(t+1) \\
\varepsilon_{3}(t+1)
\end{array}\right]
\end{gathered}
$$

を用いる. こてで， $t$ は $(1) \sim(3)$ 式とは異なり，サ ンプリング回数を表わすすのとする $(t=0,1,2, \cdots)$. 
また， $a_{11}, b_{110}, b_{111}$ などは未知パラメータであり, $c_{1}$ $\sim c_{3}$ は平衡值の影響を表わす未知の一定量, $\varepsilon_{1} \sim \varepsilon_{3}$ は 外乱，モデリング誤差，A/D変換誤差などよりなる未 知変動量である.

(4) 式にモデル規範形適応手法を応用するためには 逆システムが安定でなければならない.すなわち，

$$
\left|b_{i i 1} / b_{i i 0}\right|<1, \quad i=1,2,3
$$

この条件を十分に満たすために，乙こではサンプリン グ周期を経験的に 10 [s]とした. とのとき，同定実験 によって得られたパラメータの推定值は， $a_{11} \fallingdotseq-0.9$, $a_{21} \fallingdotseq-1, a_{31} \fallingdotseq-0.3, b_{110} \fallingdotseq 0.06, b_{111} \fallingdotseq 0.02, b_{120} \fallingdotseq$ $0.03, b_{130} \fallingdotseq-0.1, b_{220} \fallingdotseq 0.01, b_{221} \fallingdotseq 0.005, b_{230} \fallingdotseq-$ $0.01, b_{330} \fallingdotseq 2.6, b_{331} \fallingdotseq-0.4$ の程度である. $b_{110}$ と $b_{220}$ が小さいが，乙のととが本装置に対する基本的 MRAC（第 1 章で述べた恒等式で $F=1, P=Q_{r}=Q_{s}$ $=I$ (単位行列) の場合）の制御入力が振動する原因で ある。

\section{3. 制御アルゴリズム}

(1)〜 (3) 式を一般化した次式

$$
\begin{aligned}
& {\left[\begin{array}{ccc}
A_{1}\left(z^{-1}\right) & 0 \\
& \ddots & \\
& \ddots & \\
0 & & A_{l}\left(z^{-1}\right)
\end{array}\right]\left[\begin{array}{c}
y_{1}\left(t+d_{1}\right) \\
\vdots \\
y_{l}\left(t+d_{l}\right)
\end{array}\right]} \\
& =\left[\begin{array}{ccc}
B_{11}\left(z^{-1}\right) \cdots & B_{1 l}\left(z^{-1}\right) \\
\vdots & \ddots & \vdots \\
\vdots & \ddots & \vdots \\
B_{l 1}\left(z^{-1}\right) \cdots & B_{l l}\left(z^{-1}\right)
\end{array}\right]\left[\begin{array}{c}
u_{1}(t) \\
\vdots \\
u_{l}(t)
\end{array}\right] \\
& +\left[\begin{array}{c}
c_{1} \\
\vdots \\
c_{l}
\end{array}\right]+\left[\begin{array}{c}
\varepsilon_{1}\left(t+d_{1}\right) \\
\vdots \\
\varepsilon_{l}\left(t+d_{l}\right)
\end{array}\right]
\end{aligned}
$$

について制御アルゴリズムを述べる．乙こで，lは入 出力変数の個数, $d_{1} \sim d_{l}$ はむだ時間, $c_{1} \sim c_{l}$ は末知定 数, $\varepsilon_{1} \sim \varepsilon_{l}$ は規範モデル出力にくらべて十分小さい 振動性の外乱である。（6)式は多変数系に対する非 干渉制御のための入出力表現法としてよく知られてい $3^{8), 91}$. 以下では簡単のためにベクトル・行列形式で

$$
A\left(z^{-1}\right) y(t+d)=B\left(z^{-1}\right) u(t)+C+\varepsilon(t+d)
$$

と表わす. そして, (i ) $|x|<1$ のとき $\operatorname{det}|B(x)| \neq$ 0 , (ii ) $d_{1} \sim d_{l}$ は既知, (iii) $A_{i}, B_{i j}(i, j=1 \sim l) の$ 次数の上限は既知之仮定する. 制御アルゴリズムの目 的は，出力 $y(t)$ を与えられた規範モデル出力 $y_{M}(t)$ に追従させると同時に，外乱 $\varepsilon(t)$ に起因する制御入力 $u(t)$ の短周期振動成分を抑制するととである.

\section{1 間 接 法}

(7) 式の両辺に $\left(1-z^{-1}\right) / F\left(z^{-1}\right)$ を掛けると, 一定值 Cが消去されて

$$
\alpha\left(z^{-1}\right) y_{f}(t+d)=B\left(z^{-1}\right) U_{f}(t)+\delta_{f}(t+d)
$$

となる.とこで,

$$
\begin{aligned}
& \alpha\left(z^{-1}\right)=\left(1-z^{-1}\right) A\left(z^{-1}\right) \\
& U_{f}(t)=\frac{1}{F\left(z^{-1}\right)} U(t) \\
& U(t)=u(t)-u(t-1) \\
& y_{f}(t)=\frac{1}{F\left(z^{-1}\right)} y(t) \\
& \delta_{f}(t+d)=\frac{1-z^{-1}}{F\left(z^{-1}\right)} \varepsilon(t+d)
\end{aligned}
$$

であり， $F\left(z^{-1}\right)$ は安定なモニック多項式である. 間接 法としては，(8)式に基づいて係数 $\alpha\left(z^{-1}\right), B\left(z^{-1}\right)$ を 推定し，その推定值を真值とみなして制御則を計算す る. 仮定によって $\delta_{f}(t+d)$ は微小であるから，同定 法としては固定トレースゲインアルゴリズムのような 式誤差法が適用でき，推定值は漸近的に一定とみなす ことができる．乙れを $\hat{\alpha}\left(z^{-1}\right), \hat{B}\left(z^{-1}\right)$ とする. $\hat{\alpha}, \hat{B}$ に併う同定誤差を $\hat{\delta}_{f}(t+d)$ と表わせば，間接法は系 の入出力関係を $(8)$ 式の代わりに次式とみなすととに ほかならない。

$$
\hat{\alpha}\left(z^{-1}\right) y_{f}(t+d)=\hat{B}\left(z^{-1}\right) U_{f}(t)+\hat{\delta}_{f}(t+d)
$$

さて, 追従目的を達成するために, 制御器の構造と して，つぎのような制御結果を与えるあのを考える.

$$
\begin{gathered}
P\left(z^{-1}\right)\left[y(t+d)-y_{M}(t+d)\right] \\
\quad=Q_{r}\left(z^{-1}\right) \hat{R}\left(z^{-1}\right) \hat{\delta}_{f}(t+d)
\end{gathered}
$$

ここで, $P\left(z^{-1}\right), \hat{R}\left(z^{-1}\right), Q_{r}\left(z^{-1}\right)$ はモニック多項式を 要素とする $l \times l$ の対角行列で, $P$ と $Q_{r}$ は安定とす る. (11)，(12)式から $\hat{\delta}_{f}(t+d)$ を消去して整理する 亡,

$$
P y_{M}(t+d)=\left(F P-\hat{\alpha} Q_{r} \hat{R}\right) y_{f}(t+d)+Q_{r} \hat{R} \hat{B} U_{f}(t)
$$

となるが, $U_{\boldsymbol{f}}(t)$ が未来の出力に依存しないためには, $F P-\hat{\alpha} Q_{r} \hat{R}$ が因数 $z^{-d}=\operatorname{diag}\left[z^{-d_{1}}, \cdots, z^{-d} l\right]$ を含む 必要がある.また, $u(t)$ を $(9)$ 式の第 3 式から計算す るために，右辺第 2 項は $U(t)$ とその他の項に分解さ れなければならない. そこで,

$$
\begin{aligned}
& F\left(z^{-1}\right) P\left(z^{-1}\right)= \hat{\alpha}\left(z^{-1}\right) Q_{r}\left(z^{-1}\right) \hat{R}\left(z^{-1}\right) \\
&+z^{-d} Q_{s}\left(z^{-1}\right) \hat{S}\left(z^{-1}\right) \\
& Q_{r}\left(z^{-1}\right) \hat{R}\left(z^{-1}\right) \hat{B}\left(z^{-1}\right)=F\left(z^{-1}\right) \hat{B}(0)+z^{-1} \hat{K}\left(z^{-1}\right)
\end{aligned}
$$

とおく．乙こで， $Q_{s}$ と $\hat{S}$ は対角行列である. $F, P$, $Q_{r}, Q_{s}$ が与えられると， $\hat{\alpha} Q_{r}$ と $Q_{s}$ の対応する対角 成分が既約のとき，(14)，(15)式は， $\hat{R} ， \hat{S} ， \hat{K}$ につ いて解くことができる. これらを(13)式に代入すると

$$
P y_{M}(t+d)=Q_{s} \hat{S} y_{f}(t)+\hat{B}(0) U(t)+\hat{K} U_{f}(t-1)
$$

$$
\therefore U(t)=\hat{B}^{-1}(0)\left\{P y_{M}(t+d)\right.
$$$$
\left.-Q_{s} \hat{S} y_{f}(t)-\hat{K} U_{f}(t)\right\}
$$

となる.そして，プラントに印加する入力 $u(t)$ は， 
(9)式の第 3 式および振幅制限 $u_{\mathrm{min}} \leqq u(t) \leqq u_{\max }$ を 考慮して, 次式で与える.

$$
\begin{aligned}
& u_{i}^{0}(t)=u_{i}(t-1)+U_{i}(t), i=1,2,3 \\
& u_{i}(t)=\left\{\begin{array}{lll}
u_{i \max } & \left(u_{i}^{0}(t)>u_{i \max }\right. & \text { のとき) } \\
u_{i \min } & \left(u_{i}^{0}(t)<u_{i \min }\right. & \text { のとき) } \\
u_{i}^{0}(t) & (\text { 上記以外 })
\end{array}\right.
\end{aligned}
$$

なお，(13)式の両辺に $F\left(z^{-1}\right)$ を掛けて添字 $f$ を省 いた式から $U(t)$ を仮に計算したとすれば，てれは (12)式の両辺にFを掛けたととになるから，閉ループ 系の特性多項式行列は $F P$ となり, 初期誤差あるいは 外乱に対するレギュレーションの速度が遅くなる.し たがって，(15)式のように分解する必要がある.

$3.2 F\left(z^{-1}\right), \boldsymbol{P}\left(z^{-1}\right), \boldsymbol{Q}_{r}\left(z^{-1}\right), \boldsymbol{Q}_{s}\left(z^{-1}\right)$ について (18)式の $u^{0}(t)$ ，が振幅制限内に納まっている場合を 考えよう. (12)式より

$$
y(t)=y_{M}(t)+P^{-1}\left(z^{-1}\right) Q_{r}\left(z^{-1}\right) \hat{R}\left(z^{-1}\right) \hat{\delta}_{f}(t)
$$

となる. 一方，(11)式の両辺に $F\left(z^{-1}\right)$ を掛け，これ に(20)式を代入すると

$$
\begin{aligned}
U(t)= & \hat{B}^{-1}\left\{\hat{\alpha}\left[y_{M}(t+d)+P^{-1} Q_{r} \hat{R} \delta_{f}(t+d)\right]\right. \\
& \left.-F \hat{\delta}_{f}(t+d)\right\} \\
= & \hat{B}^{-1}\left\{\hat{\alpha} y_{M}(t+d)-P^{-1}\left[F P-\hat{\alpha} Q_{r} \hat{R}\right] \delta_{f}(t+d)\right\}
\end{aligned}
$$

ここで， $\hat{\alpha}$ および $P$ が対角行列であることを用いた. 上式に(14)式を代入すると

$$
\begin{aligned}
U(t)= & \hat{B}^{-1}\left(z^{-1}\right) \hat{\alpha}\left(z^{-1}\right) y_{M}(t+d) \\
& +\hat{B}^{-1}\left(z^{-1}\right) P^{-1}\left(z^{-1}\right) Q_{s}\left(z^{-1}\right) \hat{S}\left(z^{-1}\right) \hat{\delta}_{f}(t)
\end{aligned}
$$

を得る. (20), (21) 式は閉ループ系の出力と入力であ るから，

$$
\left.\begin{array}{l}
\Delta y(t)=H\left(z^{-1}\right) \hat{\delta}_{f}(t), \quad H=P^{-1} Q_{r} \hat{R} \\
\Delta U(t)=-G\left(z^{-1}\right) \hat{\delta}_{f}(t), \quad G=P^{-1} Q_{s} \hat{S}
\end{array}\right\}
$$

とおけば， $\Delta y(t)$ が追従誤差であり， $\left[\left(1-z^{-1}\right) \hat{B}\right]^{-1}$ $\Delta U(t)$ が制御入力 $u(t)$ の振動成分である. したがっ て，大力の平滑化のためには，(10) および (22) 式の第 2 式の観点から， $1 / F$ および $G$ の高周波ゲインが小 さくなるように $F, P, Q_{r}, Q_{s}$ を調節する必要があ る.

ここでは第 2 章に述べた制御対象の場合に有効であ った二つの方法を述べる.

(A) 低域通過フィルタの利用

この方法では，(10)と (22)式に含まれる $1 / F\left(z^{-1}\right)$ と $P^{-1}\left(z^{-1}\right) Q_{s}\left(z^{-1}\right)$ を低域通過フィルタにするとの立場加 ら，つぎのように指定する.

$$
\left.\begin{array}{l}
F\left(z^{-1}\right)=\left(1+f z^{-1}\right)^{2} \\
P\left(z^{-1}\right)=\left(1+p z^{-1}\right) \mathrm{I} \\
Q_{s}\left(z^{-1}\right)=\left(1+q_{s} z^{-1}\right) \mathrm{I} \\
Q_{r}\left(z^{-1}\right)=\mathrm{I}, \mathrm{I} \text { は } l \times l \text { 単位行列 }
\end{array}\right\}
$$

ここで, $f, p, q_{s}$ は設計定数であり, $-1<f \leq 0$,

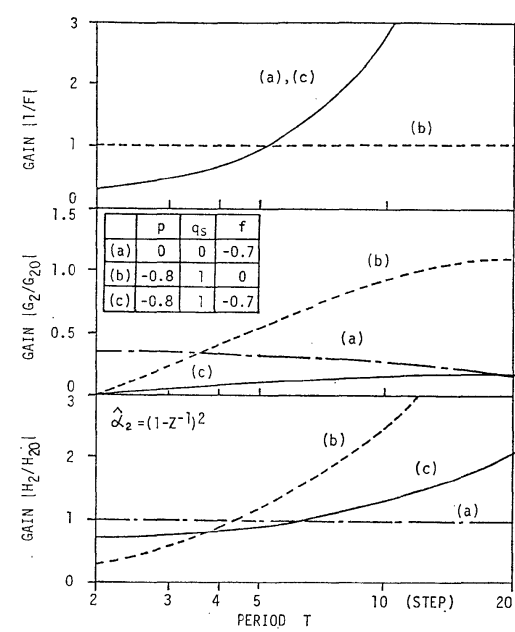

Fig. 4 Frequency response curves given by the method (A)

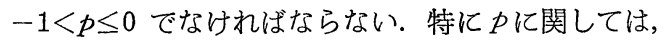
インパルス外乱に対するレギュレーションの時定数が $T_{p}=-1 / \log _{e}(-p)[\mathrm{step}]$ となるととを考慮して， - 1 よりやや大きめに選ぶ必要がある5. さて，第 2 章の 制御対象の場合には,

$$
\hat{\alpha}\left(z^{-1}\right)=\operatorname{diag}\left[1+\hat{\alpha}_{i 1} z^{-1}+\hat{\alpha}_{i 2} z^{-2}, i=1,2,3\right] \text { (24) }
$$

であるから，(14)式より

$$
\begin{aligned}
& \hat{R}\left(z^{-1}\right)=\operatorname{diag}\left[1+\hat{r}_{i 1} z^{-1}, i=1,2,3\right] \\
& \hat{S}\left(z^{-1}\right)=\operatorname{diag}\left[\hat{s}_{i 0}+\hat{s}_{i 1} z^{-1}, i=1,2,3\right] \\
& \hat{r}_{i 1}=q_{s}-\frac{\left(q_{s}-f\right)^{2}\left(q_{s}-p\right)}{q_{s}^{2}-\hat{\alpha}_{i 1} q_{s}+\hat{\alpha}_{i 2}} \\
& \hat{s}_{i 0}=2 f+p-\hat{\alpha}_{i 1}-\hat{r}_{i 1} \\
& \hat{s}_{i 1}=f^{2}+2 p f-\hat{\alpha}_{i 2}-\hat{\alpha}_{i 1} \hat{r}_{i 1}-\hat{s}_{i 0} q_{s}
\end{aligned}
$$

となる. ここで, $\hat{\alpha}\left(z^{-1}\right)=\operatorname{diag}\left[\hat{\alpha}_{1}\left(z^{-1}\right), \hat{\alpha}_{2}\left(z^{-1}\right), \hat{\alpha}_{3}\left(z^{-1}\right)\right]$ に第 2 章で述べた数值 $\hat{\alpha}_{1}\left(z^{-1}\right)=\left(1-z^{-1}\right)\left(1-0.9 z^{-1}\right)$, $\hat{\alpha}_{2}\left(z^{-1}\right)=\left(1-z^{-1}\right)^{2}, \quad \hat{\alpha}_{3}\left(z^{-1}\right)=\left(1-z^{-1}\right)\left(1-0.3 z^{-1}\right)$ を代 入し, (21) 式から求めた対角行列 $G\left(z^{-1}\right), H\left(z^{-1}\right)$ の 周波数特性を示したのが Fig. 4 である. 第 2 成分の みを示したが，他の成分も同様の傾向を示す.

図に招いて，Tは正弦波信号の周期をサンプリン グ回数で表示したあのであり $(z=\exp (2 \pi j / T), j=$ $\sqrt{-1}), G_{20}$ と $H_{20}$ は基本的 MRAC の場合である. したがって, $\left|G_{2} / G_{20}\right|<1$ となる $T$ の範囲において, 入力振動は基本的 MRACの場合よりも平滑化される. 図中(c)のグラフでは $\left|G_{2} / G_{20}\right|$ が $T \leqq 20$ [step] に おいて1より十分に小さくなっている.

(B) 2 次規範の利用

一般に入力を平滑化すれば，追従䛊差は逆に増加す る. そこで, 入出力の振動の大小関係の目安として 
908 昭和 62 年 9 月

$$
\left.\begin{array}{l}
\Delta \tilde{U}(t)=-P^{-1}\left(z^{-1}\right) \hat{S}\left(z^{-1}\right) \hat{\delta}_{f}(t) \\
\Delta \tilde{y}(t)=P^{-1}\left(z^{-1}\right) \hat{R}\left(z^{-1}\right) \hat{\delta}_{f}(t)
\end{array}\right\}
$$

を導入し， $\hat{\delta}_{f}(t)$ を白色雑音と仮定するととによって 2 次規範

$$
J=\mathrm{E}\left[\Delta \tilde{y}^{\mathrm{T}}(t) \Delta \tilde{y}(t)+\rho \Delta \tilde{U}^{\mathrm{T}}(t) \Delta \tilde{U}(t)\right]
$$

が最小となるように $P\left(z^{-1}\right), \hat{R}\left(z^{-1}\right), \hat{S}\left(z^{-1}\right)$ を決定す る. ここで $\rho$ は非負の重みであり， $\rho=0$ のときには $\Delta \tilde{y}(t)$ の分散が最小, $\Delta \tilde{U}$ の分散が最大となるが, $\rho$ を大きくするに従って $\Delta \tilde{U}$ の分散はしだいに小さく なる.したがって，○によって入力平滑の程度を調節 できる. (14) 式の両辺に $P^{-1}\left(z^{-1}\right) \hat{\delta}_{f}(t+d)$ を掛けると, $\Delta \tilde{U}$ と $\Delta \tilde{y}$ の関係はつぎのようになる.

$$
\hat{\alpha} Q_{r} \Delta \tilde{y}(t+d)=Q_{s} \Delta \tilde{U}(t)+F \hat{\delta}_{f}(t+d)
$$

この係数行列はすべて対角であるから，上式は $l$ 個の 互いに独立な 1 入力・1出力系の集まりである.

例として，(A) と同様に第 2 章の制御対象の場合を 考える.ただし，ここでは

$$
\left.\begin{array}{l}
F\left(z^{-1}\right)=1+f z^{-1}, Q_{r}\left(z^{-1}\right)=\left(1+q_{r} z^{-1}\right) \mathrm{I} \\
Q_{s}\left(z^{-1}\right)=\left(1+q_{s} z^{-1}\right) \mathrm{I}
\end{array}\right\}
$$

とする. (28)式の第 $i$ 成分 $\Delta \tilde{y}_{i}$ と $\Delta \tilde{U}_{i}$ の状態変数 表示は

$$
\begin{aligned}
& \boldsymbol{x}_{i}(t+1)=\boldsymbol{A}_{i} \boldsymbol{x}_{\imath}(t)+\boldsymbol{B}_{i} \Delta \tilde{U}_{i}(t)+\boldsymbol{C}_{i} \hat{\delta}_{f i}(t+1) \\
& \Delta \tilde{y}(t)=\boldsymbol{H}^{\mathrm{T}} \boldsymbol{x}_{i}(t)
\end{aligned}
$$
ただし

$$
\begin{aligned}
& \boldsymbol{A}_{i}=\left[\begin{array}{lll}
-\gamma_{i 1} & 1 & 0 \\
-\gamma_{i 2} & 0 & 1 \\
-\gamma_{i 3} & 0 & 0
\end{array}\right], \quad \boldsymbol{B}_{i}=\left[\begin{array}{c}
1 \\
q_{s} \\
0
\end{array}\right], \quad \boldsymbol{C}_{i}=\left[\begin{array}{c}
1 \\
f \\
0
\end{array}\right], \\
& \boldsymbol{H}=\left[\begin{array}{l}
1 \\
0 \\
0
\end{array}\right] \\
& \hat{\alpha}\left(z^{-1}\right) Q_{r}\left(z^{-1}\right)=\operatorname{diag}\left[1+\gamma_{i 1} z^{-1}+\gamma_{i 2} z^{-2}\right. \\
& \left.+\gamma_{i 3} z^{-3}, i=1,2,3\right]
\end{aligned}
$$

となるから，乙れに対応する $P_{i}\left(z^{-1}\right)$ は Riccati 代数 方程式

$$
\begin{aligned}
& \boldsymbol{S}_{i}=\boldsymbol{A}_{i}^{\mathrm{T}} \boldsymbol{S}_{i} \boldsymbol{A}_{i}+\boldsymbol{H} \boldsymbol{H}^{\mathrm{T}}-\boldsymbol{L}_{i} \boldsymbol{L}_{i}^{\mathrm{T}}\left(\rho+\boldsymbol{B}_{i}^{\mathrm{T}} \boldsymbol{S}_{i} \boldsymbol{B}_{i}\right) \\
& \boldsymbol{L}_{i}=\boldsymbol{A}_{i}^{\mathrm{T}} \boldsymbol{S}_{i} \boldsymbol{B}_{i} /\left(\rho+\boldsymbol{B}_{i}^{\mathrm{T}} \boldsymbol{S}_{i} \boldsymbol{B}_{i}\right)
\end{aligned}
$$

を解くことにより

$$
\begin{aligned}
\hat{P}_{i}\left(z^{-1}\right) & =\operatorname{det}\left[\mathrm{I}-\left(\boldsymbol{A}_{i}-\boldsymbol{B}_{i} \boldsymbol{L}_{i}^{\mathrm{T}}\right) z^{-1}\right] \\
& =1+P_{i 1} z^{-1}+P_{i 2} z^{-2}+P_{i 3} z^{-3}
\end{aligned}
$$

と求まる ${ }^{11)}$. とれを(14)式に代入すると

$$
\left.\begin{array}{l}
\hat{R}_{i}\left(z^{-1}\right)=1+\hat{r}_{i 1} z^{-1} \\
\hat{S}_{i}\left(z^{-1}\right)=\hat{s}_{i 0}+\hat{s}_{i 1} z^{-1}+\hat{s}_{i 2} z^{-2} \\
\hat{r}_{i 1}=q_{s}-\frac{\left(q_{s}-f\right)\left(q_{s}^{3}-p_{i 1} q_{s}^{2}+p_{i 2} q_{s}-p_{i 3}\right)}{\left(q_{s}^{2}-\hat{\alpha}_{i 1} q_{s}+\hat{\alpha}_{i 2}\right)\left(q_{s}-q_{r}\right)} \\
\hat{s}_{i 0}=p_{i 1}+f-\hat{\alpha}_{i 1}-q_{r}-\hat{r}_{i 1} \\
\hat{s}_{i 1}=p_{i 2}+f p_{i 1}-\hat{\alpha}_{i 2}-\hat{\alpha}_{i 1}\left(q_{r}+\hat{r}_{i 1}\right)-\hat{r}_{i 1} q_{r}-\hat{s}_{i 0} q_{s} \\
\hat{s}_{i 2}=p_{i 3}+f p_{i 2}-\hat{\alpha}_{i 2}\left(q_{r}+\hat{r}_{i 1}\right)-\hat{\alpha}_{i 1} \hat{r}_{i 1} q_{r}-\hat{s}_{i 1} q_{s}
\end{array}\right\}
$$

第 23 巻 第 9 号

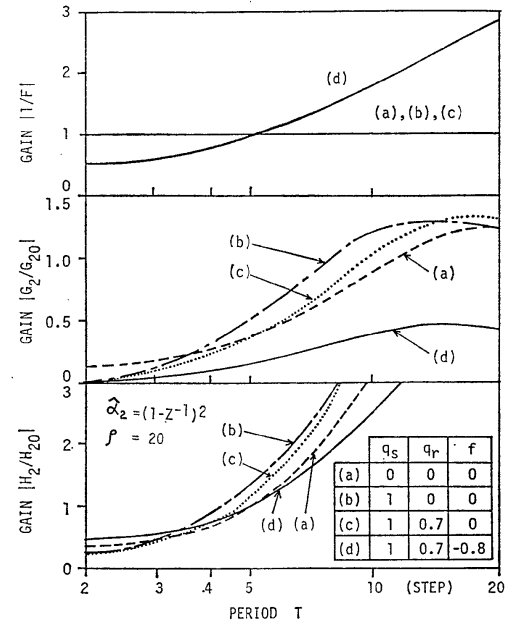

Fig. 5 Frequency response curves given by the method (B)

となる. (30)式を用いて Fig. 4 と同様に $\hat{\alpha}_{2}\left(z^{-1}\right)=$ $\left(1-z^{-1}\right)^{2}$ に対する $G_{2}\left(z^{-1}\right)$ と $H_{2}\left(z^{-1}\right)$ の周波数特性 を調べたのが Fig. 5 である. ここで， $\rho=20$ とした が, $\left|G_{2} / G_{20}\right|$ が(b), (c), (d)の順に小さくなり, $F, Q_{r}, Q_{s}$ のそれぞれが入力平滑化の機能を果たして いるととがわかる.

\section{3 直 接 法}

上に述べた間接法のアルゴリズムは，容易に直接法 に変換できる．すなわち，(16)式右辺の形式で出力の 移動平均值 $P\left(z^{-1}\right) y(t+d)$ を予測し，その予測值を $P\left(z^{-1}\right) y_{M}(t+d)$ とおくことによって(17)式から $U(t)$ を決定すればよい，したがって，直接法における入出 力の表現は,

$$
\begin{aligned}
P\left(z^{-1}\right) y(t+d)= & B(0) U(t)+K\left(z^{-1}\right) U_{f}(t-1) \\
& +S\left[Q_{s} y_{f}(t)\right]+\xi_{f}(t+d)
\end{aligned}
$$

となる. ここで, $R, S, K$ は恒等式

$$
\left.\begin{array}{c}
F\left(z^{-1}\right) P\left(z^{-1}\right)=\alpha\left(z^{-1}\right) Q_{r}\left(z^{-1}\right) R\left(z^{-1}\right) \\
+z^{-d} Q_{s}\left(z^{-1}\right) S\left(z^{-1}\right) \\
Q_{r}\left(z^{-1}\right) R\left(z^{-1}\right) B\left(z^{-1}\right)=B(0) F\left(z^{-1}\right)+z^{-1} K\left(z^{-1}\right)
\end{array}\right\}
$$

の解であり, $\xi_{f}(t+d)$ は次式で定義される.

$$
\xi_{f}(t+d)=Q_{r}\left(z^{-1}\right) R\left(z^{-1}\right) \delta_{f}(t+d)
$$

閉ループ系における入出力の振動成分は，(31)式に 式誤差法を適用したときの推定值 $\hat{B}(0), \hat{K}\left(z^{-1}\right), \hat{S}$ $\left(z^{-1}\right)$ が時不変とみなせる状態において，つぎのよう に評価できる. 同定誤差を $\hat{\xi}_{f}(t+d)$ とすると，入出 力関係は,

$$
\begin{aligned}
P y(t+d)= & \hat{B}(0) U(t)+\hat{K} U_{f}(t-1) \\
& +Q_{r} \hat{S} y_{f}(t)+\hat{\xi}_{f}(t+d)
\end{aligned}
$$

であるから，てれと(16)式より 


$$
y(t)=y_{M}(t)+P^{-1} \hat{\xi}_{f}(t)
$$

となる.一方，(16)式の両辺に $F\left(z^{-1}\right)$ を代入したの

ち，(34)式を代入すると

$$
\begin{gathered}
F P y_{M}(t+d)=Q_{s} \hat{S}\left\{y_{M}(t)+P^{-1} \hat{\xi}_{f}(t)\right\} \\
+\left[F \hat{B}(0)+z^{-1} \hat{K}\right] U(t) \\
\therefore \quad\left[F P-Q_{s} \hat{S} z^{-d}\right] y_{M}(t+d) \\
=P^{-1} Q_{s} \hat{S} \hat{\xi}_{f}(t)+\left[F \hat{B}(0)+z^{-1} \hat{K}\right] U(t)
\end{gathered}
$$

この式は午長でわかりにくいから（32)式を考慮して $F P-Q_{s} \hat{S} z^{-d}$ および $F \hat{B}(0)+z^{-1} \hat{K}$ を近似的に $\widehat{\alpha Q_{r} R}$ および $\widehat{Q_{r} R B}$ と表わすと, 次式が得られる.

$$
U(t)=\left[\widehat{Q_{r} R B}\right]^{-1}\left\{\widehat{\alpha Q_{r} R} y_{M}(t+d)-P^{-1} Q_{s} \hat{S} \hat{\xi}_{f}(t)\right\}
$$

さて，直接法についてはてれまでに多くのアルゴリ ズムが提案されているが，その代表的なあのとして Landau らの方法 ${ }^{22}{ }^{20)}$ と市川の方法9'を本手法と比較 するとつぎのようになる．制御対象は

$$
\alpha\left(z^{-1}\right) y(t+d)=B\left(z^{-1}\right) U(t)+\delta(t+d)
$$

とする. まず, Landau らの方法では, 恒等式 (32), 入出力表現式(31) および制御則(16)に対応するあのは

$$
\begin{aligned}
& P=\alpha R+z^{-d} S \\
& P y(t+d)=F\left[R B u_{f}(t)+S y_{f}(t)\right]+R \delta(t+d) \\
& \widehat{R B} u_{f}(t)+\hat{S} y_{f}(t)=P y_{M f}(t+d)
\end{aligned}
$$

である.したがって，Py(t)に対する同定誤差を $\widehat{R \delta(t)}$ と表わせば

$$
\begin{aligned}
& y(t)=y_{M}(t)+P^{-1} \widehat{R \delta(t)} \\
& u(t)=[\widehat{R B}]^{-1}\left\{\widehat{R \alpha} y_{M}(t+d)-P^{-1} \hat{S} \widehat{R \delta(t)}\right\}
\end{aligned}
$$

となり，(38)式は $F$ を含んでいない。したがって，閉 ループ系の入出力の観点からすると, 本手法の $F=1$, $Q_{r}=Q_{s}=\mathrm{I}$ の場合に相当する.つぎに，市川の方法 は

$$
\begin{gathered}
P^{*} \Gamma=\alpha R+z^{-d} S, \quad R B=R^{*} \Gamma B(0)+z^{-1} K \\
y(t+d)=B(0)\left[R^{*} / P^{*}\right] u(t)+K u_{f}(t-1) \\
+S y_{f}(t)+R \delta_{f}(t+d) \\
\hat{B}(0)\left[R^{*} / P^{*}\right] u(t)+\hat{K} u_{f}(t-1)+\hat{S} y_{f}(t) \\
=y_{M}(t+d)
\end{gathered}
$$

と要約できる. ここで, 添字 $f$ は $1 /\left(P^{*} \Gamma\right)$ による イルタ值を表わす． $P^{*}, \Gamma, R^{*}$ は本来は対角行列で あるが，記述を簡単にするためにとてではスカラーと した. (39)式より

$$
\left.\begin{array}{l}
y(t)=y_{M}(t)+\widehat{R \delta_{f}(t)} \\
u(t)=[\widehat{R B}]^{-1}\left\{\widehat{R \alpha y_{M}}(t+d)-\hat{S} \widehat{R \delta_{f}(t)}\right\}
\end{array}\right\}
$$

となるから，乙机は本手法の $F=P^{*} \Gamma, P=Q_{r}=Q_{s}$ $=\mathrm{I}$ の場合に相当する.

なお，追従誤差が零へ収束するための条件は，(31)
式，(37)式の第 2 式および(39)式の第 2 式に関する同 定がおの拉のの出力成分でとに行われるので，スカ ラ一系の場合之同一である。したがって，あし仮に $\delta(t+d) \equiv 0$ であるならば，本手法抢よび市川の方法は 無条件で収束する. これに対し, Landauの方法では, (37)式からわかるように未知パラメー夕は $F\left(z^{-1}\right)$ を 介して観測されるから， $F\left(z^{-1}\right)$ 亿関する正実条件が必 要である ${ }^{2), 10)}$. 実際には $\delta(t+d) \equiv 0$ であるから, 追 従誤差は完全には零とならず，同定が式誤差法によっ て行われるため，推定值にあバイアス誤差を生じる. しかしながら，本章の最初に述べたように $\delta(t+d)$ は 十分小さいと仮定しているから, バイアス誤差は小さ く, 制御系の安定性には問題ないもの之思われる.

\section{4. 実験}

制御実験は間接法之直接法によって行った。まず間 接法では, 推定すべきパラメータは, (24) 式の $\alpha$ 之 (4) 式の $b$ の合計 15 個の係数であり，乙れらを $y_{1}, y_{2}, y_{3}$ に関する三つの固定トレースゲインアルゴリズムで推 定した. その初期值は，ゲイン行列が $50 \mathrm{I}$ ，パラメー 夕は 2 章に示した值である．推定值を得たのち(14)， (15)式から $\hat{R}$ と $\hat{S}$ を計算するが, $P\left(z^{-1}\right), F\left(z^{-1}\right)$, $Q_{r}\left(z^{-1}\right), Q_{s}\left(z^{-1}\right)$ およびこれに対応する $\hat{R}$ と $\hat{S}$ の形は 低域通過フィルタ法では (23) と (25) 式, 2 次規範を利 用する方法では (29) と (30)式である. 入力の振幅制限 は, Fig. 2 と Fig. 3 亿みられる強度の非線形特性を 線形近似するために

$$
5 \leqq u_{1} \leqq 10,2.5 \leqq u_{2} \leqq 10,2 \leqq u_{3} \leqq 10
$$
とした.

間接法による制御結果を Fig. 6, Fig. 7 亿示す.

Fig. 6 は基本的 MRAC すなわち $F=1, P=Q_{r}=Q_{s}$ $=\mathrm{I}$ の場合である. 出力 $y_{1}, y_{2}, y_{3}$ はいずれあ破線 で示された規範モデル出力によく追従しているが，入 力 $u_{1}$ 之 $u_{2}$ は不必要な短周期振動を含んでいる. そ の原因を $u_{2}$ について調べてみると，(21)式の右辺第 2 項より,

$$
U_{2} \text { の振動成分 }=\left(\hat{S}_{2} / \hat{B}_{22}\right) \hat{\delta}_{f 2}-\left(\hat{B}_{23} \hat{S}_{3} / \hat{B}_{22} \hat{B}_{33}\right) \hat{\delta}_{f 3}
$$

となる. 上式に $\hat{\delta}_{f 2} \fallingdotseq\left(1-z^{-1}\right) \varepsilon_{2}, \hat{\delta}_{f 3} \fallingdotseq\left(1-z^{-1}\right) \varepsilon_{3}$ を代 入し， $u_{2}=\left[1 /\left(1-z^{-1}\right)\right] U_{2}$ であるととを使えば， $u_{2}$ の振動成分 $\fallingdotseq\left(\hat{S}_{2} / \hat{B}_{22}\right) \varepsilon_{2}-\left(\hat{B}_{23} \hat{S}_{3} / \hat{B}_{22} \hat{B}_{33}\right) \varepsilon_{3}$

と近似できる. そして，第 2 章に示した推定值によっ て計算すると, $\hat{S}_{2} / \hat{B}_{22}=\left(2-z^{-1}\right) /\left(0.01+0.005 z^{-1}\right)$, $-\hat{B}_{23} \hat{S}_{3} / \hat{B}_{22} \hat{B}_{33}=0.01\left(1.3-0.3 z^{-1}\right) /\left(0.01+0.005 z^{-1}\right)$ $\left(2.6-0.4 z^{-1}\right)$ である. したがって，周期 $2[\mathrm{step}]$ の 
振動成分 $(z=-1)$ のみに着目すれば,

$$
u_{2} \text { の振動成分 } \fallingdotseq 600 \varepsilon_{2}+1.1 \varepsilon_{3}
$$

となり，左辺は図より約 $2 \mathrm{~V}$ であるから， $\varepsilon_{2} \fallingdotseq 0.003 \mathrm{~V}$ と推定される.乙れは線形近似誤差あるいは $12 \mathrm{bit} ・$ $10 \mathrm{~V}$ の A/D 変換器誤差のオーダであるから, $u_{2}$ の 振動は結局，そのような必然的な誤差が $\hat{B}_{22}=0.01+$ $0.005 z^{-1}$ の微小な係数によって増幅されたものと考え るととができる． $u_{1}$ についても同様である. Fig. 7 は, 上記の振動を除去するために Fig. 4 の（c）に相 当する低域通過フィルタ法を用いた場合であるが，

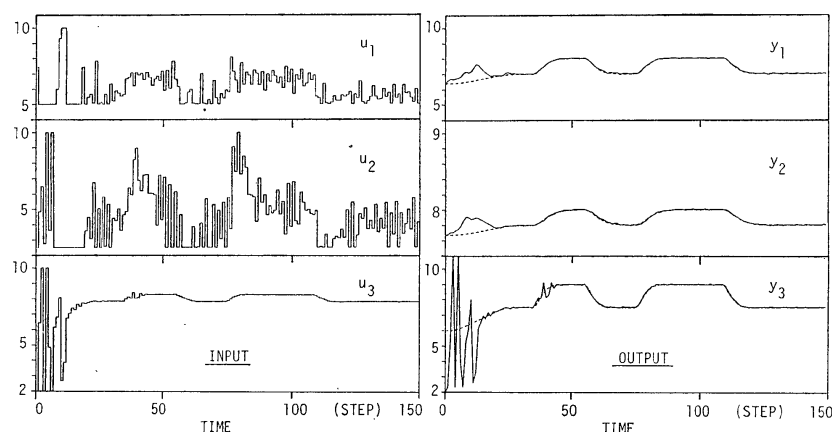

Fig. 6 Experimental result by the basic MRAC scheme
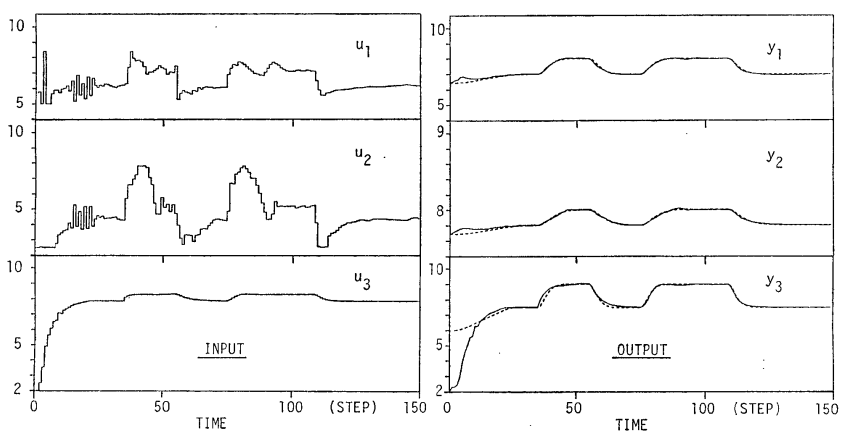

Fig. 7 Experimental result by the indirect MRAC scheme (A) where $P\left(z^{-1}\right)=1-0.8 z^{-1}, Q_{s}\left(z^{-1}\right)=1+z^{-1}$ and $F\left(z^{-1}\right)=(1-$ $\left.0.7 z^{-1}\right)^{2}$

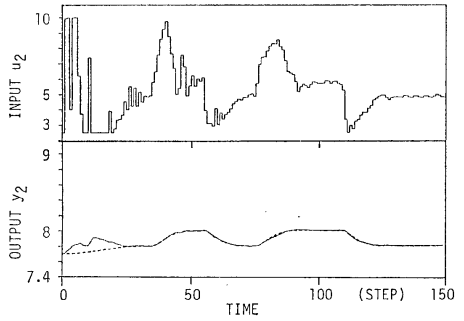

Fig. 8 Experimental result by the direct MRAC scheme where $P\left(z^{-1}\right)=1-0.8 z^{-1}, Q_{s}\left(z^{-1}\right)=$ $1+z^{-1}$ and $F\left(z^{-1}\right)=\left(1-0.7 z^{-1}\right)^{2}$
Fig. 4 から予想されたように $u_{1}, u_{2}$ はよく平滑化さ れている. 2 次規範を利用する方法によっても同様の 平滑化が達成できる.

つぎに直接法であるが， $P, F, Q_{r}, Q_{s}$ は(23)式と した．乙の場合の推定すべきパラメータは，B(0)に6 個, $K\left(z^{-1}\right)$ に 12 個, $S\left(z^{-1}\right)$ 飞 個含まれ, 合計 24 個 である．との場合にあ推定は固定トレースゲインアル ゴリズムで行い，その初期值は第 2 章に示した值を用 いて(14)式で計算した。制御結果は, $P=1-0.8 z^{-1}$, $Q_{s}=1+z^{-1}, \quad F=\left(1-0.7 z^{-1}\right)^{2}$ の場合が Fig. 8 亿示 されている. パラメータ数が多いために適 応の初期段階での振動がやや大きいが, $t \geqq 100$ [step] 以後は Fig. 7 とほぼ同一と なっている.

以上の実験結果では Fig. 4, Fig. 5 から 予想された入力平滑化が達成されたが，乙 れが本実験のようなむだ時間 1 [step]の 1 次系の特殊性ではなく，より高次の系に対 してあ有効であるととを確認するためにデ ィジタルシミュレーションを行った結果を

Fig. 9 亿示す. 制御対象は,

$$
\begin{aligned}
& A\left(z^{-1}\right) y(t+d)=B\left(z^{-1}\right) u(t)+C \\
& \quad+h L(t)+\varepsilon(t+d)
\end{aligned}
$$

で記述される 1 入力・ 1 出力系である. ここで, $A\left(z^{-1}\right)=1+a_{1} z^{-1}+a_{2} z^{-2}+a_{3} z^{-3}$, $B\left(z^{-1}\right)=b_{0}+b_{1} z^{-1}, d=2, \quad\left(a_{1}, a_{2}, a_{3}, b_{0}, b_{1}\right)$ $=(-2.1,1.53,-0.365,1.0,0.4: t \leqq 24)$, $(-2.0,1.53,-0.356,0.9,0.5: t \geqq 25), h$ $=0.4, C=1, L(t)=(0: t \leqq 499), \quad(1: t \geqq$ $500)$ であり, $L(t)$ は既知信号, $\varepsilon$ は標準偏 差 0.05 の正規白色雑音である. アルゴリ ズムとしては 2 次規範を利用する万法を用 い， $F, Q_{r}, Q_{s}$ は (29)式とした. 基本的 MRAC の (a)にくらべて, Fig. 5 と同様 に(b)，(c)，(d)の順に入力が平滑化さ

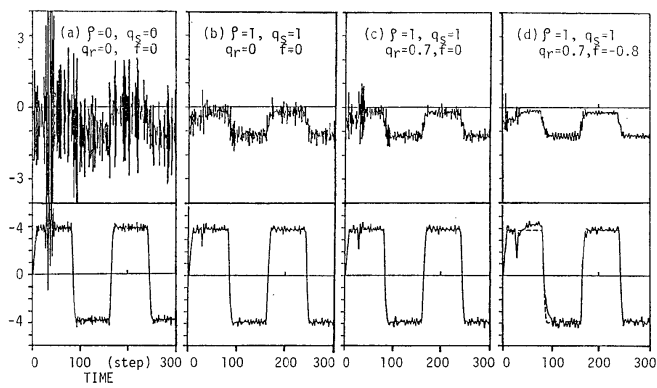

Fig. 9 Simulation results of the indirect MRAC scheme (B) for the plant (42) 


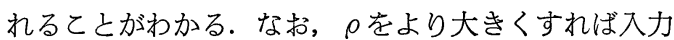
の振動は減小するが, 出力のゆらぎが大きくなる.

\section{5. 結 言}

ここでは，モデル規範形適応制御 (MRAC) の応用 に関する基礎研究の一つとして，3 入力 ・ 3 出力のプ ロセス制御系での実験について述べた，系の入出力 関係は，変数間の相互作用とむだ時間を考慮しうる必 要最小限のパラメータを含む線形離散時間モデルで近 似し，入力に作用する非線形性に対しては入力の振幅 を制限するとととした．制御アルゴリズムとしては， 規範モデルへの出力の追従と同時に制御の滑らかさを 目的とし, 基本的 MRAC を改良して平滑化因子 $F$, $P, Q_{r}, Q_{s}$ を含める方策を示した. 制御実験では, 追従と平滑の両目的が達成され，乙のような若干の改 良・工夫のあとで MRAC がプロセス制御に有効なも のであるととが確かめられた。また，アルゴリズムに 関しては，実験とは別の 1 入力・1出力系のモデルに ついてディジタルシミュレーションを行い, その入力 平滑化の機能が一般的なあのであることを示した．今 後の課題としては，制御系そのものの能力を十分に発 揮させるために入力の振幅制限を除去するとと，ある
いは非線形性を考慮しうる簡単な入出力間のモデルや これに対する同定手法の開発であると思われる。

\section{参 考 文 献}

1）計測自動制御学会編：小特集・適応制御, 計測之制御, 23-5 (1984)

2) I.D. ランダウ, 富塚：適応制御システムの理論と実際， オーム社 (1981)

3) K. S. Narendra and R. V. Monopoli (ed.): Applications of Adaptive Control, Academic Press (1981)

4) 小西，ほか：圧力制御系へのモデル規範形適応手法の一 応用, 計測自動制御学会論文集, 21-9，996/998 (1985)

5) 小西，ほか：入力平滑特性を有するモデル規範形適応制 御系の一設計法, 日本機械学会論文集 ( C 編), 52-476, 1362/1369 (1986)

6) 田村捷利：モデル 規範形適応制御とセルフチューニング レギュレータ，計测と制御，23-5，428/432 (1984)

7) 成田誠之助：ディジタルシステム制御, 昭晃堂 (1980)

8) G. C. Goodwin, et al.: Discrete-Time Multi Variable Adaptive Control, IEEE Trans. Automatic Control, AC-25-3, 449/456 (1980)

9) 市川邦彦：制御系設計法 [V] ，計測と制御，23-11，959/ 967 (1984)

10) I. D. Landau and R. Lozano: Unification of Discrete Time Explicit Model Reference Adaptive Control Designs, Automatica, 17-4, 593/611 (1981)

11）小西, 芳村, 添田: $\mathrm{CE}$ 原理に基づく適応レギュレータ の可能収束点, 計測自動制御学会論文集, 16-6,838/845 (1980) 